\title{
QUALIDADE DA PAISAGEM: ESTUDO DE CASO NA FLORESTA OMBRÓFILA MISTA
}

\author{
Elaine de Cacia de Lima $^{1}$ \\ Carlos Roberto Sanquetta ${ }^{2}$ \\ Flávio Felipe Kirchner ${ }^{3}$ \\ Eliane Regina Ferretti ${ }^{4}$
}

\begin{abstract}
RESUMO
A pesquisa desenvolvida em uma propriedade inserida no bioma da Floresta Ombrófila Mista, localizada no município de General Carneiro, no estado do Paraná, objetivou realizar um diagnóstico da qualidade da paisagem ao longo de uma série temporal, com a utilização de geotecnologias como o sensoriamento remoto e o geoprocessamento. O estudo proporcionou a elaboração dos produtos de uso e cobertura do solo referente aos anos de 1952, 1980 e 2000, os quais foram cruzados a partir da programação em LEGAL (linguagem espacial para geoprocessamento algébrico) no software SPRING 3.6, gerando as cartas de qualidade da paisagem de 1952-1980 e 1980-2000. Através de análises constatou-se variações significativas relacionadas à constituição das características elementares que compõem e integram os aspectos da paisagem, caracterizando uma melhoria na qualidade paisagística do recorte espacial.

Palavras-Chaves: geoprocessamento, sensoriamento remoto, paisagem
\end{abstract}

\section{LANDSCAPE QUALITY: A CASE STUDY IN THE ARAUCARIA FOREST}

\begin{abstract}
This research was carried out in a property located in the Araucaria Forest Biome, General Carneiro municipality, Paraná State, Brazil. It aims to analyze the landscape quality changes along a time series by using geotechnology, such as remote sensing and geoprocessing. This work provided land use and forest coverage maps respective to 1952, 1980 and 2000, which were integrated through the LEGAL (spatial language for algebraic geoprocessing) programming language on the SPRING 3.6 software. The landscape quality changes in the property for the periods 1952-1980 and 1980-2000 were examined. The analysis showed significant variations related to the landscape quality during the periods of study. It was concluded that the landscape quality changes positively along time in the study site.
\end{abstract}

Key words: geoprocessing, remote sensing, landscape

\section{INTRODUÇÃO}

Os estudos da paisagem são considerados como importante recurso para as questões ambientais, uma vez que revela a forma de como o espaço geográfico se encontra em função de sua utilização.A qualidade da paisagem refere-se ao grau de excelência ambiental e visual que esta apresenta, podendo ser estudada sobre a

\footnotetext{
1 elainecacia@ig.com.br, Geógrafa, MSc em Manejo Florestal do Curso de Pós-Graduação em Engenharia Florestal da UFPR e Professora do Departamento de Geografia da UTP, Rua Guararapes, 2270, ap71 bloco B, Portão.

${ }^{2}$ sanqueta@floresta.ufpr.br. Engenheiro Florestal, M Sc, Dr., Professor do Departamento de Ciências Florestais da UFPR, Av. Lothário Meissner, 3400, Jardim Botânico.

${ }^{3}$ kirchner@floresta.ufpr.br. Engenheiro Florestal, M Sc, Dr., Professor do Departamento de Ciências Florestais da UFPR, Av. Lothário Meissner, 3400, Jardim Botânico.

${ }^{4}$ eliane.Ferretti@utp.br. Geógrafa, M Sc, Dra., Professora do Departamento de Geografia da UTP, Rua Sydnei Antônio Rangel Santos, 238, Santo Inácio.
}

Recebido para publicação: 29/10/2003

Aceito para publicação: 22/04/2004 
dinâmica espaço-temporal. $\mathrm{O}$ fator temporalidade refere-se às mudanças dos elementos formadores da paisagem ao longo de uma série temporal, pela eliminação de alguns elementos e inserção de outros. Já a espacialidade refere-se às mudanças de áreas e/ou formas que estes elementos sofreram ao longo dos anos.

A floresta é um dos elementos que mais caracteriza a dinâmica espaço-temporal, devido às pressões ocorridas pela expansão dos centros urbanos ou mudanças no uso e ocupação do solo, ocasionando a sua supressão ou fragmentação.

Com a utilização de geotecnologias, como o sensoriamento remoto e o geoprocessamento têm-se ferramentas eficazes para analisar a qualidade dos elementos de uma determinada paisagem. A partir disso pode-se viabilizar um melhor planejamento do uso dos recursos naturais e o manejo sustentável nas florestas e/ou povoamentos florestais, permitindo com que estes elementos correspondam à disponibilidade dos aspectos físicos que compõem o meio (erodibilidade dos solos, as condições climáticas, disponibilidade hídrica, inclinação do terreno, entre outros), de maneira mais equilibrada e menos agressiva. Portanto, essa é uma ferramenta de grande utilidade na gestão de propriedades florestais.

A pesquisa apresentada neste artigo teve como objetivos: o diagnóstico das mudanças ocorridas na paisagem, por meio da realização de um estudo sobre a dinâmica espaço-temporal da paisagem, analisando três momentos distintos (1952, 1980 e 2000); e aplicação das geotecnologias para a elaboração dos produtos cartográficos relacionados com a qualidade da paisagem, como suporte técnico à gestão ambiental.

\section{REFERENCIAL TEÓRICO}

Para Dolfuss (1973), a paisagem é formada de elementos geográficos que se articulam uns em relação aos outros. Pertencem alguns ao domínio natural físico, como o substrato geológico, a geomorfologia, o clima, o solo e a hidrografia. Os demais constituem o domínio vivo, a biosfera, formada pelo conjunto das comunidades florísticas e faunísticas que desenvolvem o ciclo da vida, utilizando o suporte constituído pelo domínio natural abiótico. Finalmente, os grupos humanos são os atores decisivos, que transformam, modificam e alteram os domínios ambientais. Modelam grande parte das paisagens terrestres, cujos conjuntos são desigualmente frágeis e mutáveis.

A qualidade que a paisagem apresenta, segundo Ignacio et al. (1984) citados por Pires (1993), refere-se ao grau de excelência das características visuais que apresenta, contribuindo para que esta não seja alterada ou destruída.

A paisagem ao longo da dinâmica espaço-temporal tem os seus elementos modificados e transformados. Segundo Turner (1990), considerando que a percepção da evolução da paisagem se manifesta com a passagem do tempo, qualquer alteração no seu desenvolvimento natural é associada à ocorrência de um desequilíbrio, sendo de origem antropogênica ou não. Assim, estas perturbações e alterações contribuem para produzir uma estrutura específica de paisagem, sua própria heterogeneidade pode restringir a dispersão espacial de um distúrbio. Esse último aspecto é particularmente importante no contexto de manejo da paisagem, para estabelecer medidas de proteção aos ecossistemas frágeis.

A avaliação da paisagem pode ser realizada através de geotecnologias aplicadas à integração dos componentes do meio, proporcionando análises espaciais e temporais.

A geotecnologia é a arte e a técnica de estudar a superfície da Terra e adaptar as informações às necessidades dos meios físicos, químicos e biológicos. Fazem parte da geotecnologia o sensoriamento remoto, a geoestatística e o geoprocessamento (Silva, 1999).

O sensoriamento remoto, segundo Novo (1995), é definido como a utilização de sensores para a aquisição de informações sobre objetos ou fenômenos da superfície terrestre, não havendo a necessidade de contato direto entre eles. Os sensores seriam os equipamentos capazes de coletar energia proveniente do objeto, convertê-la em sinal passível de ser registrado e apresentá-lo em forma adequada à extração de informações.

O termo geoprocessamento é utilizado para representar as técnicas matemáticas $\mathrm{e}$ 
computacionais destinadas ao tratamento da informação geográfica, (Câmara; Medeiros, 1998).

A partir do conceito de geoprocessamento é importante ressaltar a existência do SIG (Sistema de Informações Geográficas), criado para compor um sistema com os objetivos de: armazenar, manipular, cruzar e sobrepor as características geográficas integrantes da paisagem.

Para Aronoff (1991) um SIG é concebido para a coleta, armazenamento e análise de objetos e fenômenos onde a localização geográfica é uma característica importante ou crítica para a análise.

Desta forma, a geotecnologia foi utilizada para sobrepor e cruzar informações com o intuito de indicar áreas em que a paisagem apresenta graus de antropização decorrente da disponibilidade e qualidade dos recursos naturais e da utilização do espaço pelas atividades antrópicas.

\section{MATERIAIS E MÉTODOS}

O recorte espacial definido para este estudo é de propriedade das Indústrias Pizzatto (Fazendas Santa Cândida, São Pedro I e II), localizada no município de General Carneiro, Região Sul do estado do Paraná, contendo aproximadamente 4.400 ha de área (figura 1).

A escolha do recorte espacial foi motivada pela importância do bioma da Floresta Ombrófila Mista (floresta com araucária) e a crescente preocupação com sua conservação, haja vista as várias formas de pressão relacionadas ao modelo de ocupação do estado ocorrida no passado. Uma outra razão para a escolha da área é que se trata de uma típica propriedade florestal na região sul do estado do Paraná, onde se produz madeira e outros produtos não madeiráveis da floresta, tanto de povoamentos, como da floresta nativa, apresentando assim, vários elementos formadores da paisagem.

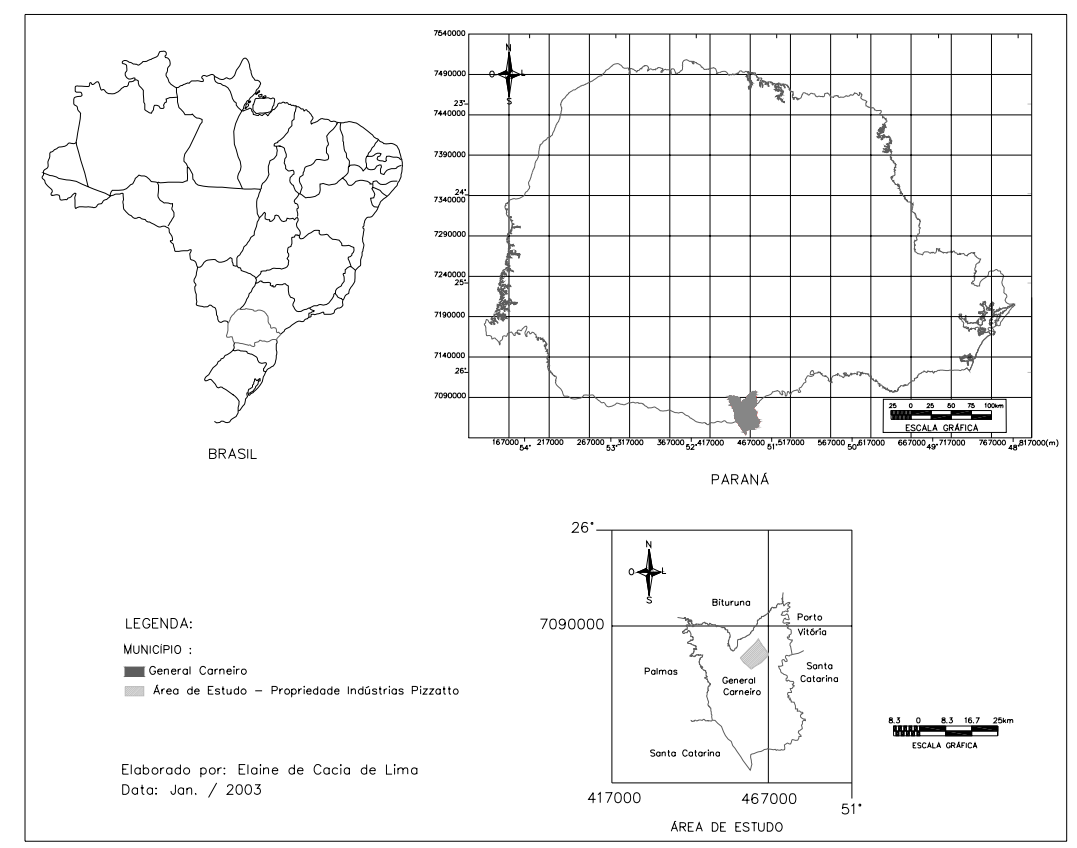

Figura 1: Localização da Área de Estudo

Figure 1: Study site

O trabalho foi dividido em 3 (três) etapas principais: campo, escritório e laboratórios.

$\mathrm{Na}$ etapa de campo, ocorreu o reconhecimento da área para obter informações dos aspectos abióticos, bióticos e antrópicos; a aquisição de pontos de controle para georreferenciamento da imagem de satélite e identificação dos elementos da paisagem; e a composição de acervo fotográfico destes elementos.

$\mathrm{Na}$ etapa referente ao escritório ocorreram as pesquisas bibliográficas; estruturação da pesquisa e análise dos resultados. 
$\mathrm{Na}$ etapa de elaboração de produtos referente à utilização de laboratórios, foi realizada a fotointerpretação de fotografias aéreas em escala 1:25.000, para obtenção das Cartas de Uso e Cobertura do solo dos anos de 1952 e 1980; a interpretação visual da imagem de satélite Ikonos II, apresentando resolução de $4 \times 4 \mathrm{~m}$ (bandas multiespectrais) para elaboração da Carta de Uso e Cobertura do solo do ano de 2000; realização do cruzamento entre as cartas temáticas de uso e cobertura, através de programação LEGAL (Linguagem espacial para geoprocessamento algébrico) no SPRING versão 3.6 (INPE), utilizando a lógica booleana, operador AND (a operação lógica do tipo A AND B retorna todos os elementos contidos na intersecção entre A e B), para elaboração da Carta da Qualidade da Paisagem de 1952-1980 e 1980-2000, sugerindo as seguintes classes: altíssimo grau de antropização, alto grau de antropização, médio grau de antropização e baixo grau de antropização; para a elaboração da carta de qualidade foram agrupadas as classes das cartas de uso e cobertura do solo em três classes (áreas em processo de estabilização, áreas sob manejo florestal e áreas com alteração positiva e negativa), para padronização e minimização de classes.

Dentre as áreas em processo de estabilização foram classificadas as que abrangem os elementos como florestas em estágios inicial, intermediário e avançado de sucessão ecológica. Nessas áreas a Floresta Ombrófila Mista vem se recuperando do processo antrópico sofrido em função das variadas formas de utilização do espaço geográfico. Estão inseridas também nessa classe as formações pioneiras, áreas alagadas que contribuem para a manutenção dos recursos hídricos, assim como os campos naturais (estepes) e os campos com araucária, que são cenários de uma beleza cênica característica da região.

Dentre as áreas sob manejo florestal foram identificadas as que passam por processo de manejo para produção de madeira, incluindo os plantios com pinus e com araucária, para abastecimento da indústria. Essas áreas contribuem para a estabilidade das demais, fazendo com que áreas em processo de estabilização deixem de ser utilizadas para a produção florestal. Foram identificadas também nesta classe, as áreas de uso em reforma, que no momento da aquisição das fotografias aéreas e da imagem de satélite eram desprovidas de vegetação, mas que são utilizadas para a produção florestal.

Dentre as áreas alteradas, negativa ou positivamente identificadas como áreas modificadas e transformadas pelas ações antrópicas, artificializando a paisagem. Entretanto estes impactos podem trazer benefícios ou malefícios à visualização da paisagem e conseqüentemente ao sistema ambiental. Classificadas como positivas, foram as construções de corpos d'água (lagos, reservatórios, etc), que contribuem para a melhoria qualitativa e quantitativa dos recursos hídricos, permitindo a manutenção da fauna local. Estas caracterizam um impacto que trouxe benefícios à qualidade visual da paisagem (especificamente para este recorte espacial); e classificadas como negativas, foram as edificações que artificializam e modificam a paisagem (apesar de necessárias para a sobrevivência e bem estar do homem), solo exposto (maior susceptibilidade erosiva) e outras formas de uso do solo de maior impacto ao meio ambiente e à paisagem. Sob o ponto de vista visual e ambiental esta classe apresenta um grau elevado de antropização.

Foi elaborada uma matriz para realizar a classificação com o objetivo de cruzar os novos temas dos três produtos cartográficos temporais, sendo realizado o cruzamento a cada dois produtos (1952-1980) e (1980-2000), o que possibilitou na elaboração das cartas de qualidade da paisagem, conforme mostra a tabela 1 . 
Tabela 1: Matriz de obtenção de classes para qualidade da paisagem

Table 1: $\quad$ Matrix of landscape quality classes

\begin{tabular}{|l|c|c|c|c|}
\hline \multicolumn{1}{|c|}{$\begin{array}{c}1952 \\
\text { e } \\
1980\end{array}$} & $\begin{array}{c}\text { Áreas em processo } \\
\text { de estabilização }\end{array}$ & $\begin{array}{c}\text { Áreas com } \\
\text { alteração positiva }\end{array}$ & $\begin{array}{c}\text { Áreas sob manejo } \\
\text { florestal }\end{array}$ & $\begin{array}{c}\text { Áreas com } \\
\text { alteração negativa }\end{array}$ \\
\cline { 2 - 5 } $\begin{array}{c}\text { Áreas em processo } \\
\text { de estabilização }\end{array}$ & $\begin{array}{c}\text { Baixo grau de } \\
\text { antropização }\end{array}$ & $\begin{array}{c}\text { Baixo grau de } \\
\text { antropização }\end{array}$ & $\begin{array}{c}\text { Médio grau de } \\
\text { antropização }\end{array}$ & $\begin{array}{c}\text { Médio grau de } \\
\text { antropização }\end{array}$ \\
\hline $\begin{array}{l}\text { Áreas com } \\
\text { alteração positiva }\end{array}$ & $\begin{array}{c}\text { Baixo grau de } \\
\text { antropização }\end{array}$ & $\begin{array}{c}\text { Baixo grau de } \\
\text { antropização }\end{array}$ & $\begin{array}{c}\text { Médio grau de } \\
\text { antropização }\end{array}$ & $\begin{array}{c}\text { Alto grau de } \\
\text { antropização }\end{array}$ \\
\hline $\begin{array}{l}\text { Áreas sob manejo } \\
\text { florestal }\end{array}$ & $\begin{array}{c}\text { Médio grau de } \\
\text { antropização }\end{array}$ & $\begin{array}{c}\text { Médio grau de } \\
\text { antropização }\end{array}$ & $\begin{array}{c}\text { Médio grau de } \\
\text { antropização }\end{array}$ & $\begin{array}{c}\text { Alto grau de } \\
\text { antropização }\end{array}$ \\
\hline $\begin{array}{l}\text { Áreas com de de } \\
\text { alteração negativa }\end{array}$ & $\begin{array}{c}\text { Médio grau de } \\
\text { antropização }\end{array}$ & $\begin{array}{c}\text { Alto grau de } \\
\text { antropização }\end{array}$ & $\begin{array}{c}\text { Alto grau de } \\
\text { antropização }\end{array}$ & $\begin{array}{c}\text { Altíssimo grau de } \\
\text { antropização }\end{array}$ \\
\hline
\end{tabular}

Com o cruzamento foram definidas quatro classes temáticas de qualidade, referente ao grau de antropização: altíssimo, alto, médio e baixo.

A classe denominada de altíssimo grau representa uma antropização intensa propiciando a inexistência de vegetação, afetando desta forma a qualidade paisagística do recorte espacial.

Como alto grau de antropização foram classificadas as áreas onde as ações do homem são constantes, mesmo estas sendo essenciais para sua sobrevivência. Entretanto estão proporcionando ao sistema ambiental uma modificação e transformação através da artificialização, afetando a qualidade visual da paisagem.

O tema médio grau de antropização refere-se às áreas que estão sob manejo florestal. Estes foram classificados como médio grau pela ocorrência de vegetação, no entanto, estas áreas estão sendo submetidas à extração de produtos madeiráveis.

O baixo grau de antropização foi classificado como a melhor área uma vez que a vegetação existente é representada por formas naturais e outras por sucessão ecológica em processo de estabilização, contribuindo para a qualidade da paisagem e para a dinâmica do recorte espacial, além de conter áreas com alteração positiva no caso específico deste recorte espacial, como lagos e reservatórios que estão contribuindo para a manutenção dos recursos hídricos.

\section{RESULTADOS E DISCUSSÕES}

\section{Qualidade da Paisagem}

De acordo com Valdivielso (1984) citado por Pires (1993), o estudo da paisagem constitui-se, em essência, na obtenção dos elementos ou unidades que a definam e na valoração dos mesmos. Em princípio qualquer método é válido e a responsabilidade do autor está em tornar explícita a base subjetiva do método escolhido, indicando os aspectos nos quais se baseou, contando para tanto com o auxílio das ciências geográficas, biológicas, psicológicas, sociais e exatas.

$\mathrm{Na}$ figura 2 observa-se o fluxograma que apresenta as classes de qualidade da paisagem identificadas e classificadas neste trabalho. 


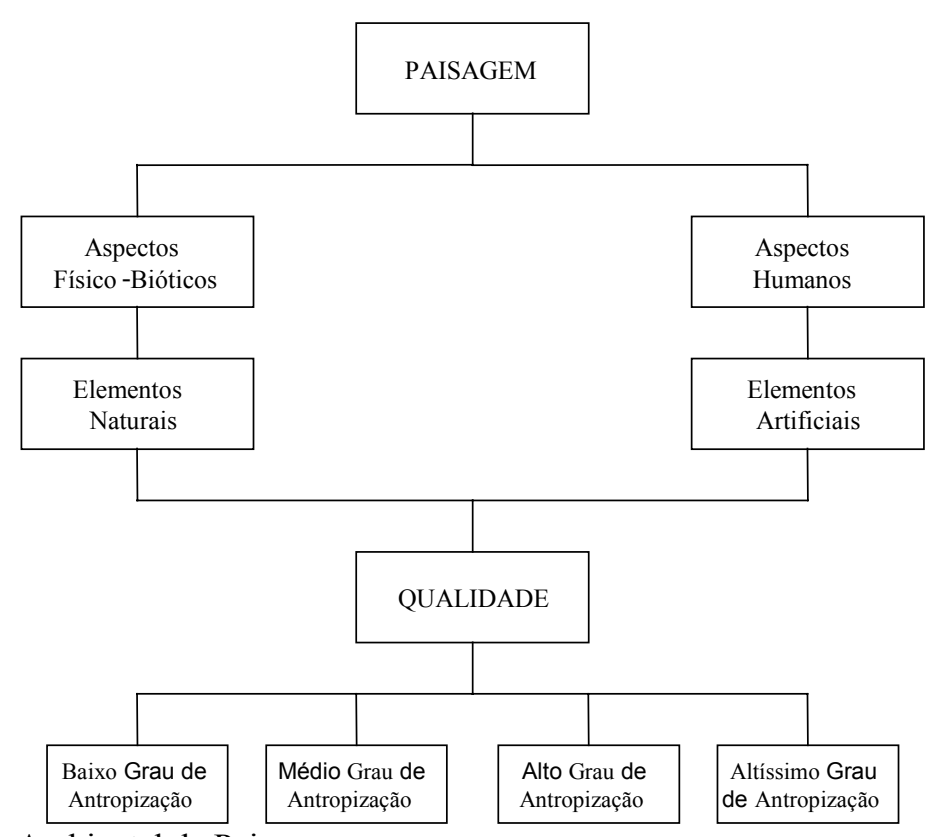

Figura 2: Qualidade Visual e Ambiental da Paisagem

Figure 2: Visual and environmental landscape quality

\begin{abstract}
Os aspectos físico-bióticos representam os elementos naturais que compõem o ambiente e estes são utilizados como recursos pelos homens. Ao explorar estes recursos o homem modifica a paisagem, além de construir diferentes elementos que artificializam a paisagem.
\end{abstract}

O grau de antropização que determinada paisagem apresenta vai depender da quantidade e da qualidade dos elementos que a compõem. Assim, um altíssimo grau de antropização refere-se a uma área em que a qualidade da paisagem se apresenta baixa, no caso específico deste trabalho refere-se a inexistência de vegetação, ou seja, um solo exposto que contribui para os processos erosivos. $\mathrm{O}$ alto grau de antropização também se refere a uma qualidade que se apresenta baixa, que neste caso é representado pelos elementos construídos pelo homem, artificializando a paisagem através de edificações o que descaracteriza a paisagem como "natural" ou menos "modificada". O médio grau de antropização indica que a alteração na paisagem ocorreu, entretanto não trouxe maiores problemas para sua qualidade, sendo representado neste trabalho pelas áreas sob manejo, onde são realizados plantios de pinus e araucária para a manutenção da indústria, estes são realizados através de adequados manejos, entretanto por ser uma área onde a ação do homem é existente esta foi classificada como médio grau. O baixo grau de antropização refere-se a áreas que apresentam as condições naturais ou semi-naturais, onde se observa que a ação antropogênica é inexistente ou pouco representativa, neste caso inclui-se nesta classe as florestas em estágios inicial, intermediário e avançado de sucessão ecológica, áreas alagadas, estepes e campos com araucária, este elementos caracterizam-se por uma alta qualidade visual. Nas figuras $3 \mathrm{e}$ 4 observa-se a qualidade da paisagem nos anos de $1952-1980$ e $1980-2000$. 


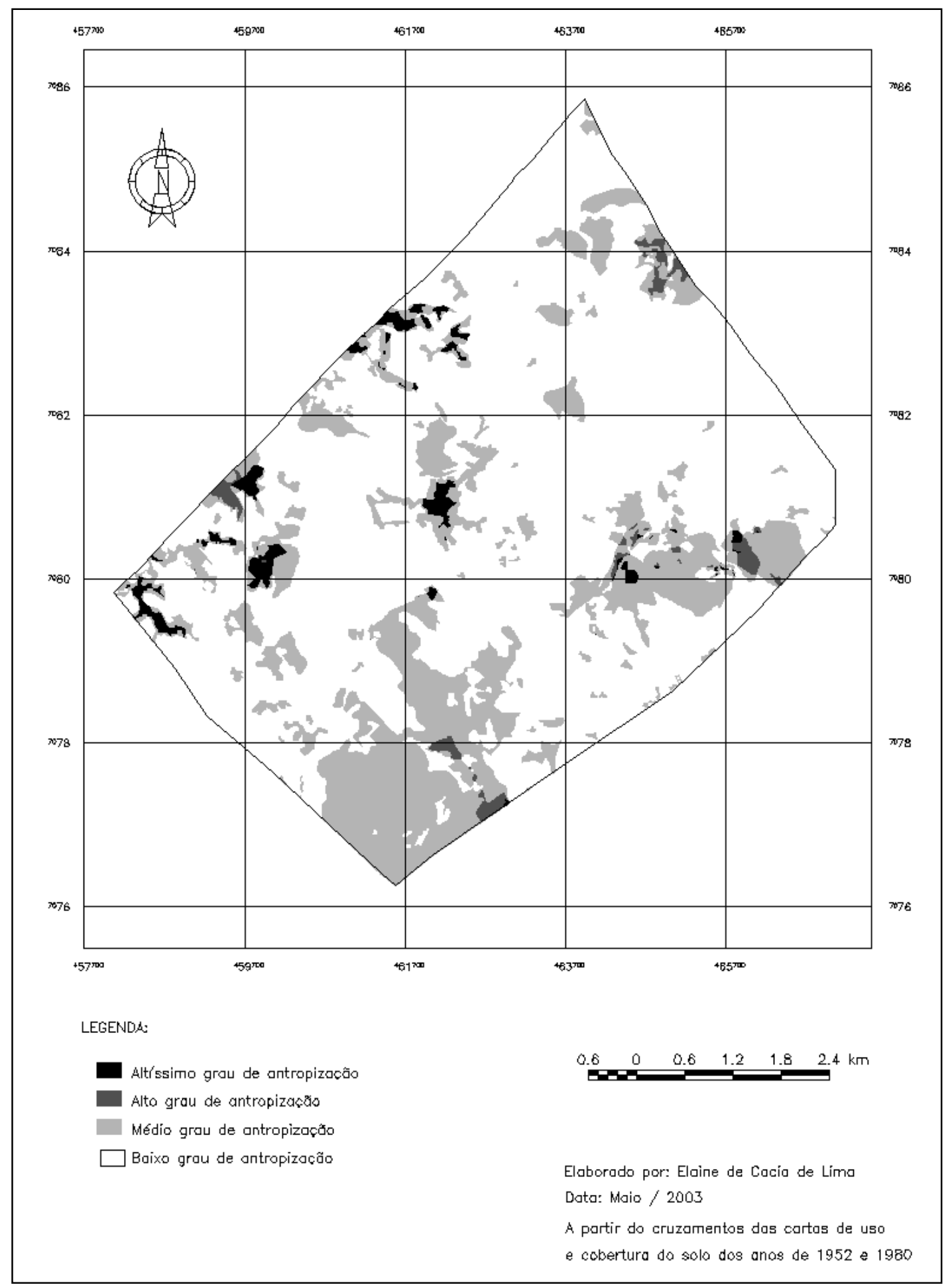

Figura 3: Qualidade da Paisagem 1952-1980

Figure 3: Landscape quality 1952-1980 


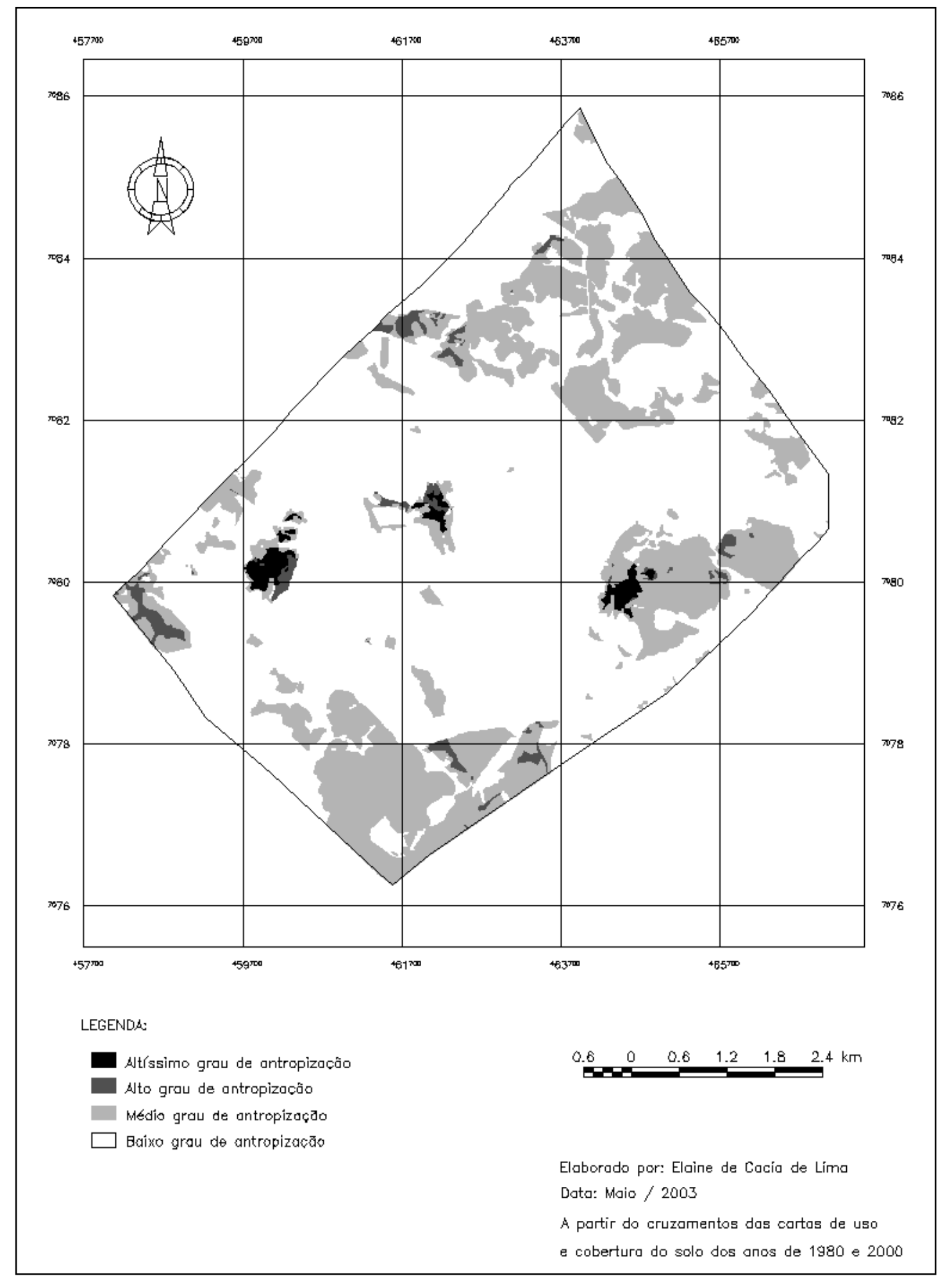

Figura 4: Qualidade da Paisagem 1980-2000

Figure 4: Landscape quality 1980-2000 


\section{Dinâmica Espaço-Temporal da Paisagem}

Através da tabela 2 e da figura 5 observa-se a distribuição das classes temáticas da qualidade da paisagem de 1952-1980 e 1980-2000. Já na tabela 3 observa-se a tabulação cruzada realizada sobre os dois produtos cartográficos, indicando áreas que passaram de uma classe para outra pelo processo da dinâmica espaço-temporal.

Tabela 2: Classes Temáticas de Qualidade da Paisagem (1952-1980) e (1980-2000)

Table 2: Thematic classes of landscape quality (1952-1980) and (1980-2000)

\begin{tabular}{|c|c|c|c|c|}
\hline \multirow{2}{*}{ Descrição } & \multicolumn{2}{|c|}{ Áreas (ha) } & \multirow{2}{*}{$\begin{array}{l}\text { Modificação de } \\
\text { Área (ha) }\end{array}$} & \multirow{2}{*}{ Porcentagem (\%) } \\
\hline & $1952-1980$ & $1980-2000$ & & \\
\hline Altíssimo grau de antropização & 83,74 & 49,16 & $-34,57$ & $-0,8$ \\
\hline Alto grau de antropização & 54,19 & 75,15 & 20,96 & 0,5 \\
\hline Médio grau de antropização & $1.008,57$ & $1.089,26$ & 80,69 & 1,8 \\
\hline Baixo grau de antropização & $3.259,03$ & $3.191,96$ & $-67,07$ & $-1,5$ \\
\hline
\end{tabular}

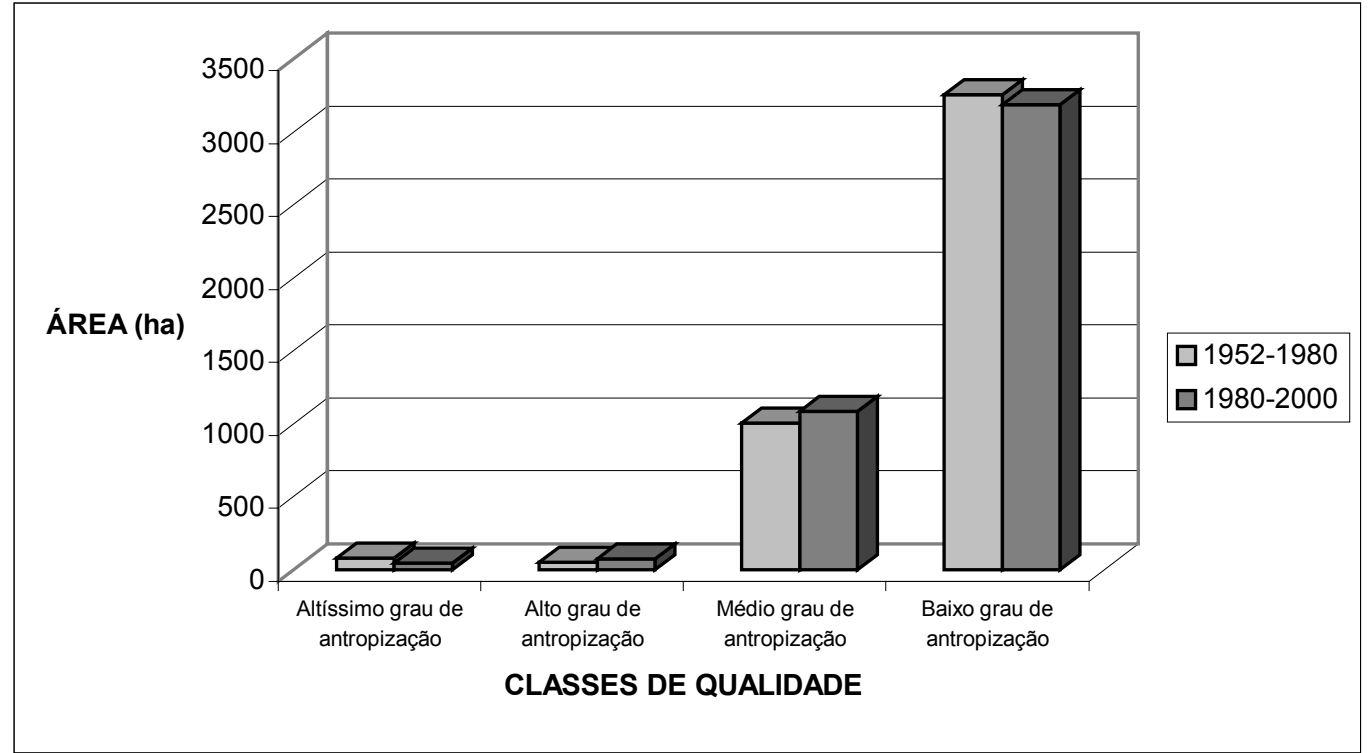

Figura 5: Distribuição das Classes Temáticas de Qualidade da Paisagem (1952-1980) e (1980-2000)

Figure 5: Distribution of thematic classes of landscape quality (1952-1980) and (1980-2000)

Tabela 3: Cruzamento das Classes Temáticas de Qualidade da Paisagem (1952-1980) e (1980-2000) Table 3: Cross of thematic classes of landscape quality (1952-1980) and (1980-2000)

\begin{tabular}{|c|c|c|c|c|}
\hline \multicolumn{5}{|c|}{ Área (ha) } \\
\hline 1980-2000- & $\begin{array}{l}\text { Altíssimo grau } \\
\text { de antropização }\end{array}$ & $\begin{array}{l}\text { Alto grau de } \\
\text { antropização }\end{array}$ & $\begin{array}{l}\text { Médiograu de } \\
\text { antropização }\end{array}$ & $\begin{array}{l}\text { Baixo grau de } \\
\text { antropização }\end{array}$ \\
\hline Altíssimo grau de antropização & 22,40 & 30,69 & 30,84 & 0,00 \\
\hline Alto grau de antropização & 0,00 & 6,78 & 47,35 & 0,15 \\
\hline Médio grau de antropização & 26,76 & 37,65 & 560,01 & 384,10 \\
\hline Baixo grau de antropização & 0,00 & 0,03 & 450,92 & $2.807,35$ \\
\hline
\end{tabular}


As principais constatações procedentes desta avaliação são decorrente das análises das tabelas 2 e 3 e da figura 5, obtendo os seguintes resultados:

- A classe de Altíssimo grau de antropização teve um decréscimo de área de 34,57 (ha) ou $0,8 \%$ da área total, sendo que 22,40 (ha) de área permaneceram ocupadas nas duas cartas e o restante de área da carta de 1952-1980 foram ocupadas em 19802000 pelas seguintes classes: alto $(30,69 \mathrm{ha})$ e médio (30,84 ha). Isso significa que a área de solo exposto classificada como altíssimo grau de antropização, teve sua área ocupada por edificações classificadas como alto grau de antropização e por áreas sob manejo identificadas por médio grau. O solo exposto propicia a existência de processos erosivos, pois a falta de vegetação aumenta o escoamento superficial, afetando o ciclo hidrológico. A inexistência de cobertura vegetal, ou seja, o solo desnudo foi identificado neste trabalho com uma qualidade baixa, desta forma, a redução de sua área constitui uma melhoria na qualidade visual $\mathrm{e}$ ambiental da paisagem.

- O tema alto grau de antropização teve um aumento de área de 20,96 (ha) ou $0,5 \%$ da área total, sendo ocupado 6,78 (ha) de área entre 1952-1980 e 19802000, ficando o restante ocupado por: médio (47,35 ha) e baixo (0,15 ha), isso indica que o aumento de área nesta classe refere-se a modificação do uso do solo, onde em 1952-1980 era apresentada como altíssimo grau de antropização parte passou para alto grau em 1980-2000, através do acréscimo de área construída.

- A classe temática de médio grau de antropização também teve um acréscimo de área de 80,69 (ha) ou $1,8 \%$ da área total, ocupando 560,01 (ha) de área entre os dois produtos cartográficos, onde o restante passou a ser ocupado pelos temas de: altíssimo
(26,76 ha), alto $(37,65 \mathrm{ha})$ e baixo (384,10 ha), apesar deste tema ter perdido área para a classe de altíssimo e alto grau de antropização, a maior área se concentrou na classe baixo, favorecendo desta forma a qualidade. $\mathrm{O}$ acréscimo desta área justifica-se pelo aumento de área destinada ao manejo florestal, a expansão destas áreas sob manejo, utilizadas para a extração dos recursos madeiráveis e não madeiráveis, permite com que a floresta nativa deixe de ser utilizada para esta finalidade e se recupere, trazendo desta forma uma melhoria para a qualidade visual e ambiental da paisagem estudada, pois através de seus estágios de sucessão ecológica, a floresta volta a se regenerar e a se estabilizar com o tempo, trazendo equilíbrio para o sistema ambiental.

- O tema baixo teve um decréscimo de área de 67,07 (ha) ou 1,5\% da área total, ficando 2807,35 (ha) de área ocupada nas duas cartas, sendo distribuído em 1980-2000 para o tema médio (450,92 ha) e alto (0,03 ha). A perda de área do tema baixo grau de antropização é justificada pelo aumento de áreas sob manejo classificadas como médio grau de antropização, pois a ação do homem é presente, entretanto por existir uma vegetação protegendo $\mathrm{o}$ solo $\mathrm{e}$ abrigando a fauna local, propicia um favorecimento para o sistema ecológico e também para as questões econômicas, uma vez que este recorte espacial é uma indústria madeireira.

- Com o decréscimo de área de solo exposto (altíssimo grau de antropização) que prejudica o sistema ambiental e com o acréscimo de área do tema médio grau (áreas sob manejo) onde estas áreas passam a ser exploradas permitindo a regeneração da floresta nativa em processos de sucessão, foi identificado que este recorte espacial passa a apresentar uma melhoria na qualidade de sua 
paisagem, tanto visual quanto ambiental.

- Outro aspecto que merece comentário é a redução do número de polígonos das áreas com alto e altíssimo grau de antropização, observadas nas figuras 3 e 4, o que implica que durante o período de análise ocorreu uma reversão do processo de fragmentação. Isto também se constitui numa melhoria ambiental na propriedade, pois a fragmentação refere-se às áreas de floresta que sofreram redução e isolamento, isto ocorre pelo desmatamento da área para determinados fins, como: comércio de madeira, ocupação da área para agricultura, urbanização, construção de indústrias, por queimadas descontroladas, entre outros fatores. Com a fragmentação há o desequilíbrio ecossistêmico, onde o principal componente constituinte do meio a ser afetado é a fauna, que passa a ter seu habitat ou parte dele destruído, tendo assim que se adaptar nos locais onde restaram florestas, outro componente a sofrer conseqüências são as espécies vegetais que passam a ocupar a borda do fragmento, ficando susceptíveis ao efeito de borda que se associa às intempéries da natureza.

Verifica-se que o recorte espacial apresentou, no decorrer da dinâmica temporal, várias mudanças em relação aos elementos formadores da paisagem. No entanto, estas mudanças ocorreram em função da dinâmica exploratória e ocupacional da região, onde em 1952 a visão de extração da madeira era diferente do que se tem nos dias atuais. $\mathrm{Na}$ atualidade a pressão existente em relação às questões ambientais tem na legislação um papel importante de conservação, conscientização e harmonização do homem com a natureza, priorizando desta forma a associação da disponibilidade dos recursos naturais às necessidades sócio-econômicas. Com esta visão, a propriedade teve sua rotina de trabalho alterada, passando a ter uma visão conservacionista. Com isso a qualidade da paisagem teve um aumento em relação ao processo de estabilização das áreas principalmente de florestas, existindo áreas próprias para as extrações e manejos florestais, permitindo, desta forma, que a propriedade tenha mais objetivos, além da extração madeireira, como a conservação da natureza que poderá ser explorada por práticas que conciliem a obtenção de recursos financeiros à proteção dos recursos naturais, como o ecoturismo quando realizado de forma sustentável.

\section{CONCLUSÕES} seguintes:

As conclusões deste trabalho são as

No decorrer da dinâmica espaçotemporal da propriedade, a qualidade da paisagem teve uma sensível melhoria em termos ambientais e paisagísticos, o que foi determinado pela redução das áreas com maior nível de alteração antrópica e pela diminuição da fragmentação ambiental dos atributos naturais na área durante a análise dos três períodos (1952, 1980 e 2000).

As ferramentas tecnológicas empregadas neste estudo foram satisfatórias para as aplicações desejadas. $O$ trabalho propiciou um procedimento metodológico que poderá ser aprofundado e melhorado para os estudos de qualidade da paisagem. Esta metodologia poderá ser utilizada em outras propriedades rurais e outros biomas para o diagnóstico das dinâmicas ocorridas na paisagem, para identificação e compreensão dos elementos que formam o meio, consistindo embasamento técnico-científico para o planejamento territorial e construção de cenários futuros para a melhor forma de utilização do espaço de um recorte específico.

Em relação às mudanças ocorridas na forma de utilização do recorte espacial, a paisagem apresentou ao longo da série temporal um acréscimo de qualidade, gerando benefícios para o ambiente, entretanto alguns procedimentos devem ser realizados e constantemente monitorados, como:

- Florestamentos das áreas de solo exposto, para minimizar os efeitos dos processos erosivos;

- Quantificar e qualificar as áreas de preservação permanente às margens dos rios, respeitando a legislação do 
código florestal (Lei 4.771 de 15-091965);

- Respeitar as limitações de inclinação do relevo e as estruturas pedológicas, para adequar as formas de utilização e ocupação do espaço;

- Permitir a estabilização das florestas em sucessão que se encontram nos estágios inicial e intermediário;

- Diminuir os efeitos de fragmentação, que alteram a dinâmica sistêmica ambiental, trazendo malefícios à fauna local, ao ciclo hidrológico, do carbono, entre outros;

- Continuamente aplicar técnicas de manejo sustentável, para aliar as características físico-bióticas às econômicas da propriedade, pois desta forma pode-se minimizar as alterações degradativas que ocorrem, por vezes em algumas propriedades florestais.

A continuidade e o aprofundamento dos resultados deste trabalho devem ser considerados, para que a qualidade da paisagem do recorte espacial permaneça com alto grau de excelência, servindo de exemplo e modelo para outras propriedades que necessitam associar a exploração às disponibilidades dos recursos naturais.

\section{BIBLIOGRAFIA CITADA}

ARONOFF, S. Geographic Information Systems: A management perspective. Ottawa: WDL Publications, 1991. 294p.
CÂMARA， G.; MEDEIROS， J. S. Geoprocessamento em Projetos Ambientais. Tutorial apresentado no Congresso GIS Brasil $1998 . \quad$ Disponível em: <www.dpi.inpe.br/cursos/gisbrasil/>. Acesso em: 25 jan. 2003.

DOLFUSS, O. Análise Geográfica. São Paulo: Difusão Européia do Livro, 1973. 130p.

FUPEF - FUNDAÇÃO DE PESQUISAS FLORESTAIS DO PARANÁ. Diagnóstico dos Remanescentes Florestais. In: Projeto de Conservação e Utilização Sustentável da Diversidade Biológica Brasileira - PROBIO, Subprojeto Conservação do Bioma Floresta com Araucária. Relatório Final, vol. I, 121p., 2001.

NOVO, E. M. L. M. Sensoriamento Remoto: princípios e aplicações. 2. ed. São Paulo: E. Blücher, 1995. 308p.

PIRES, P. S. Avaliação da qualidade visual da paisagem na Região Carbonífera de Criciúma - SC. Curitiba, 1993. 72p. Dissertação (Mestrado em Engenharia Florestal), Universidade Federal do Paraná.

SILVA, A. B. Sistemas de informações georeferenciadas: conceitos e fundamentos, Campinas, SP: Editora da Unicamp, 1999. 236p.

TURNER, M. G. Spatial and temporal analysis of landscape patterns. Landscape Ecology, Amsterdam, v. 4., 1990, p. 21-30. 